\title{
Spatial analysis and temporal trend of registered noise complaints in the city of Milan, Italy
}

\author{
R. Benocci ${ }^{1}$, S.S. Muchetti ${ }^{1}$, D. Salvi ${ }^{1}$, F. Angelini ${ }^{1}$, G. Brambilla ${ }^{2}$ and G. Zambon ${ }^{1}$ \\ ${ }^{1}$ Dipartimento di Scienze dell'Ambiente e della Terra (DISAT), Università degli Studi di Milano- \\ Bicocca, Milano \\ Italy \\ ${ }^{2}$ CNR-INM Sezione Acustica e Sensoristica “O.M. Corbino”, Roma \\ Italy
}

Received: February 3, 2020. Revised: April 20, 2020. Accepted: October 2, 2020. Published: October 16, 2020.

\begin{abstract}
Noise complaints, expressed by individuals or a group of people, are the outcome of a complex behaviour depending not only on the noise exposure and its evoked annoyance, but also on other factors such as socioeconomic ones. Noise annoyance has significant impacts on the quality of life and health of inhabitants, as well as social cohesion. Thus, noise complaints are a very important issue to tackle for national and local policy makers and for all stakeholders involved in planning and management of noise mitigation actions. Within the above framework, the present study describes the analysis of noise complaints submitted by citizens to the municipality of Milan, Italy, from years 2000 to 2015 . These complaints have been organized in a database and analyzed considering: i) types of noise source (technical facilities, music, transport infrastructures, etc.); ii) business/leisure activities (retail and catering businesses, production, service sector, etc.) and iii) outcomes of the complaints inspection by local authorities. In addition, by means of a GIS software, the territorial distribution of noise complaints has been determined according to the noise source category and disturbing activity. This analysis includes also a geo-statistical representation by density maps. The results show that, even though road traffic is the dominant noise source in residential and urban areas, the perception of other noises, such as those from industrial facilities, civil construction and social activities (parties, fairs and open air markets, residential noise, etc.), is perceived as more annoying. The results show that since 2007 the number of noise complaints (about 100-150 complaints/year) remains almost constant across the years. However, the spreading of leisure activities, malls, exhibition centers and venues, as observed for the years 2014-2015, would most likely grow them even more. This outcome can assist the local authority in the management of the activities in order to reduce their harmful impact on the population.
\end{abstract}

Keywords - Community noise, noise annoyance, noise perception, analysis of noise complaints.

\section{INTRODUCTION}

$\mathrm{U}$ RBAN noise is acknowledged as an environmental stressor, and since 1972 the World Health Organization (WHO) declared it as a pollutant [1]. In the EU countries more than 80 million people are estimated to be exposed to outdoor noise levels higher than $65 \mathrm{~dB}(\mathrm{~A})$. The European Environmental Agency (EEA) recently addressed the importance of realizing spaces at low noise pollution, denoted Quiet Areas (QA), in large built-up areas to protect the population from the harmful effects on human health [2], [3].

Transport noise (road, rail, and air) is the dominant source in urban areas [4]-[6], and to control and predict it dynamic noise mapping and predictive models have been recently introduced [7]-[11], as well as the detection of annoying events [12], [13] to provide a prompt tool to plan mitigation actions and a reliable representation of the traffic noise exposure.

Dealing with noise annoyance, several studies and metaanalyses have been published throughout the years in the attempt to derive relationships between noise exposure and elicited annoyance [14]. For instance, in 2002 the European Commission published the position paper on dose response relationships between transportation noise (road, railway and aircraft) and annoyance [2]. Further studies added relationships dealing with industrial noise [15] and wind turbine noise [16]. All these data were derived from social surveys where samples of people exposed to noise were interviewed to collect their responses on noise annoyance and other aspects.

Conversely, noise complaints are spontaneous actions, individual or collective, due not only to the noise and its evoked annoyance, but also influenced by socio-economic factors, the person's feeling to have control of the stressor (i.e. noise), as well as the knowledge of an institution to which report a complaint and the expectation of a successful feedback. Complaint data are often used as a proxy of annoyance but several studies have shown that only a small percentage of annoyed citizens actually take actions because 
of the moderating mechanisms between annoyance and complaining [17]. Several factors set limits to the interpretation and generalization of complaints, as detailed in [18], where 400 noise complaints to public authorities were analyzed by three trained psychologists. The analysis showed that people mostly complain about traffic noise (37.5\%) and sounds caused by trade or business (33.5\%). The moving road traffic (particularly trucks) and air traffic are the main sources of annoyance, and regarding trade or business noises, production sounds and air conditioning sounds play the greatest part. Intermittent and daily occurring sounds are the most annoying with effects on sleep disturbance. Results further indicate that psychological factors often determine the amount of annoyance, and this is in line with the concept of "noise" as a psychological, rather than an acoustical, term.

Furthermore, because noise complaints data are sensitive, they are seldom available in the public domain to protect privacy. Notwithstanding these difficulties, recent studies dealt with this issue, such as the survey carried out at large territorial scale in England [19], to examine relationships between the rate of noise complaints and socio-economic factors. The results suggested that the correlation is generally significant. Cities/regions with a higher proportion of young and single persons are most likely to collect noise complaints. Same results are obtained in case of high unemployment rate and high proportion of people living in flats. It has generally been found that persons, who are older, better educated, have higher income and higher social status, are more prone to express their feelings by the means of complaints than people who do not.

It has to be pointed out that noise complaints are a very important issue to tackle for national and local policy makers and for all stakeholders involved in planning and management of noise mitigation actions. Large-scale administrative data collected by municipal government are increasingly being used by researchers to better understand a host of urban phenomena and the way they are patterned over space and time [20].

There are case studies in the literature that report the analysis of noise community complaints as a result of the correlation between public noise annoyance and research trends on noise pollution [21], or the analysis of complaints to determine the relationship between the nature of the complaint and the type of noise, and the relationship between complaints and the day-night level (DNL) [22].

In this context and within the above framework of understanding the noise perception by the urban population, this paper deals with the analysis of noise complaints submitted by citizens to the municipality of Milan, Italy, in the years from 2000 to 2015 , with particular attention to its time trend, management and spatial distribution. The business/leisure activities in Milan, a large and lively city, are similar to those of other cities, at least in Western Europe. Beside the local interest of the data, the interest should be focused on the methodology applied to determine, by means of a GIS software, the territorial distribution of complaints considering the noise source categories and the annoying activities. Thus, under this perspective, the use of noise complaints can really improve the understanding about what is perceived as annoying by the population and, therefore, to help local authorities to take proper actions to reduce the harmful impacts.

\section{DATABASE OF NOISE COMPLAINTS}

In Italy the Italian law 447/1995 [23] on noise pollution has assigned to local authorities the management of noise complaints from citizens. They are responsible to plan all the necessary actions aimed at mitigating noise sources, as well as implementing the acoustic zoning of the territory in homogeneous areas and the realization of actions to reduce noise pollution where the limits set by legislation are exceeded.

Since early 80 's, outdoor noise has represented one of the major source of complaints from the citizens in Milan. In urban areas several sources contribute to noise pollution, such as: transport infrastructures (roads, railways and airports), public commercial establishments and entertainment venues (lounge bar, pub, disco club), service activities with correlated technical installations (air conditioning, ventilation), productive and artisanal activities. The complexity of these activities (for spatial localization, temporal frequency and modality of noise emission) makes the restoration of polluted areas not an easy task.

In the city of Milan, a private citizen exposed to noise nuisance can take the following actions:

a) telephone call for a MPD (Municipal Police Department) intervention, whenever it constitutes public nuisance (usually dealing with specific temporary events);

b) submission of a complaint (individual or collective) to the Municipality, whenever the noise is generated by stationary sources or transport infrastructures.

In case a) the MPD evaluates the intervention request, verifying the noise relevance in relation to maintaining public order and urban decency (as referred to the Penal Code). The authority can subsequently carry out on-the-spot inspections to identify the annoying source, ask for its immediate interruption and fine those activities not complying with the authorized opening hours.

In case b) the Municipal offices can take action, in presence of evident exceedance of the limits, when the noise source is associated with production, commercial and professional activities. Complaints dealing with neighbors noise, construction sites, roadworks for urgent restoration of public services, street cleaning and urban waste collection are not under the jurisdiction of the Municipal authorities. Upon receipt of the complaint, the Municipality starts the formal administrative procedure for the alleged acoustic pollution and requests noise measurements to the Regional Agency for Environmental Protection (ARPA).

Despite road traffic is the main noise source in urban areas, most of the complaints deal with technical installations, productive activities, music and noise of anthropic nature (screams and shouts). In fact, road traffic noise is perceived by the population as less annoying than unsteady sources, such as 
music or sources emitting impulsive or strong tonal noises as done by some technical installations in productive activities. The Municipality is also in charge of all the complaints regarding the surface public transport (including the tramway lines), with the exclusion of railways and underground metro lines.

Complainants can submit a request individually (single person or family unit) or collectively (citizens' committee). Fig. 1 shows the administrative process adopted by the Municipality of Milan for the management of complaints since 2014. This paper deals with the complaints addressed to the Municipality, excluding those related to transport infrastructure, which resulted negligible.

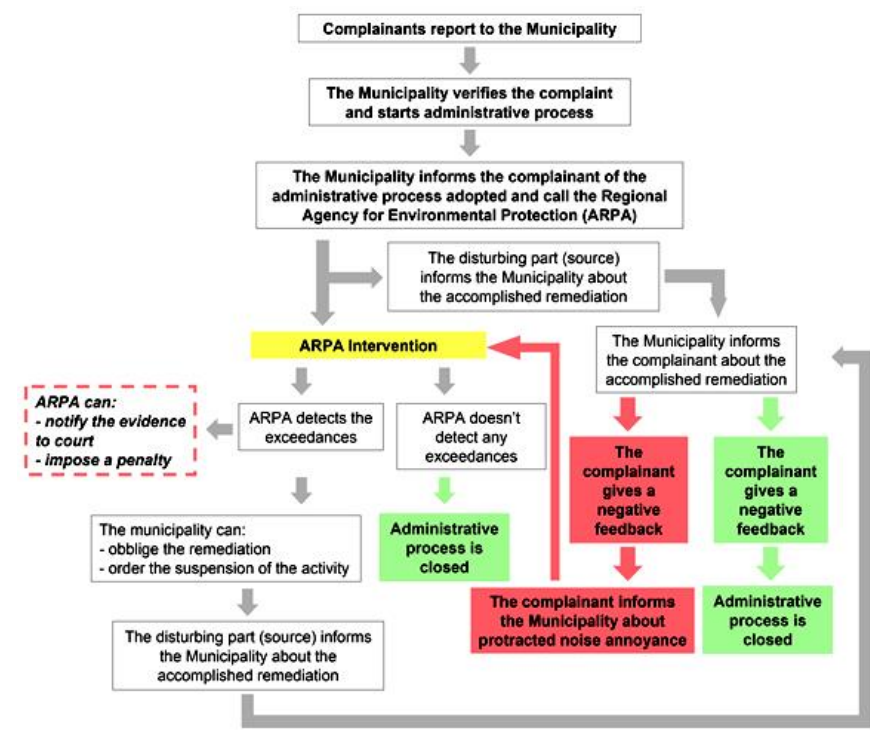

Fig. 1 flowchart of the administrative process adopted by the Municipality of Milan for the management of noise complaints since 2014

\section{MANAGEMENT OF NOISE COMPLAINTS IN THE CITY OF MILAN}

After the initial data collection in the form of both printed and digital records from the archive of the Municipality of Milan, the available information have been arranged in a digital database.

This database was organized with specific fields, such as locations of the receiver and the annoying source, details on the source, timeline of the procedure phases, remediation, etc. (see details in Fig. 2). Each complaint has been associated with an identifying code (ID Code), which refers to the date of starting the procedure. The corresponding indexing allows also a quick search in the database, making easier the GIS (Geographic Information System) post-processing spatial analysis. The geo-statistical analysis (density maps) focused on the distribution of the complaints according to the type of the annoying source and activity.

Considering the amount of data to be analyzed and the difficulty to get all the necessary information about the complaints before 2014, a different approach has been adopted for the two considered time intervals (1999-2013 records available on paper; 2014-2015 digital records available) with different degree of detail.

Complaints registered between 1999 and 2013 have been analyzed according to:

- number of submitted complaints per year;

- type of sources and type of activities reported as annoying;

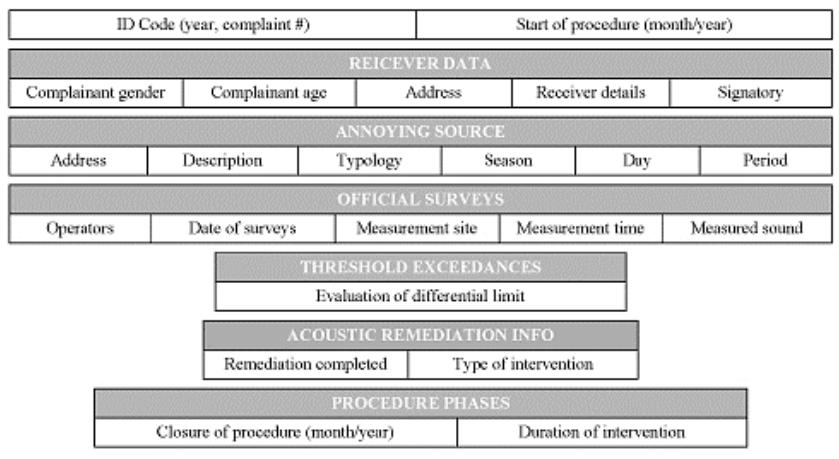

Fig. 2 organization of noise complaints database with specific fields

- type of action;

- type of proposed solution (remediation, dismissal with no remediation, suspension of the procedure);

- average duration of the complete procedure.

Complaints registered in the years between 2014 and 2015 have been analyzed in more details because of the accuracy and completeness of the available documentation. In particular, in addition to the previous information, the following data have been considered:

- type of proposed solution: remediation (direct intervention on the source, soundproofing, acoustic barrier, etc.), dismissal with and without remediation, suspension of the procedure, change of address of the complainant, etc.;

- noise level analysis at the complainant's residence;

- analysis of degree of impact, evaluated as a function of differential threshold exceedances (day and night) according to the limits of Italian legislation (referred to differential threshold exceedances).

The two digital databases (2000-2013 and 2014-2015) allowed performing a spatial analysis of the complaints by means of a geo-referenced software (GIS, Geographic Information System).

The spatial analysis for the years 2000-2013, focused on the graphical representation of the distribution of complaints according to the type of annoying source and activity.

A more accurate analysis has been performed in years 20142015 because the exact location of both the annoying sources and complainants were available.

An analysis through a GIS software allowed evaluating:

- the spatial distribution of annoying sources;

- geo-statistical distribution.

\section{A. Arrangement of the complaints submissions}

Fig. 3 shows the percentage of complaints submissions 
divided into individual or collective actions, across all the period 2000-2015 (no significant differences have been observed between the two available datasets 2000-2013 and 2014-2015). Indeed, two procedures are available for submitting a complaint, that is:

- individual submission: from one person or a family unit;

- collective submission: when complainants belong to different family units. The collective submission is usually made by groups of people sharing the same interest, as an example, residents of apartment buildings whose complaints are filed by the building manager or by citizens' committees.

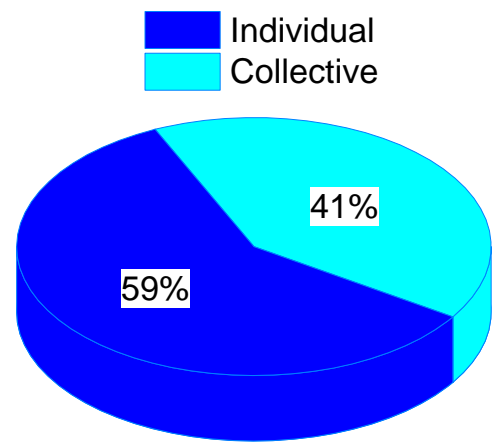

Fig 3 distribution of submitted complaints

Fig. 3 shows that individual complaints are more numerous than collectives. Actually, in terms of noise exposure of population, a larger number of people are expected to be involved in collective reported complaints. However, the collective submission does not require the complainant to declare the actual number of people he/she represents and, therefore, it is very difficult to estimate the number of people involved.

\section{RESULTS AND DISCUSSION}

\section{A. Timeline of the submitted complaints}

The analysis of the database and of the complaints sent from the municipality to the Italian National Institute of Statistics (ISTAT, a central government institution) shows the trend across the years reported in Fig. 4.

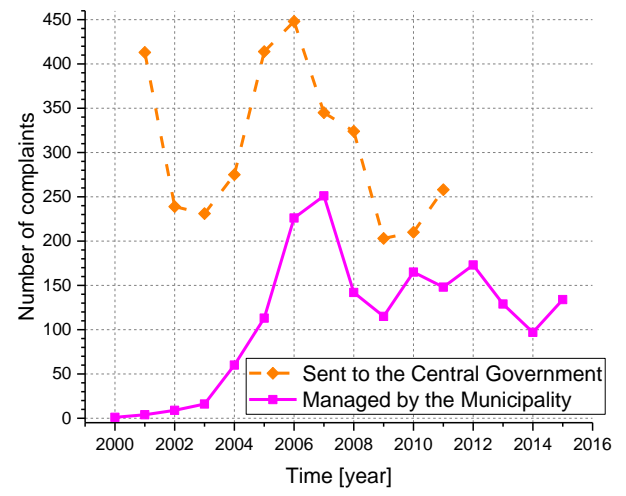

Fig 4 timeline of noise complaints reported to the Municipality (years 2000-2015)
The complaints sent to the central government were not managed by the Municipality and, in many cases, the involved parties solved independently their dispute. Fig. 4 shows an increasing trend of the number of complaints up to 2007 and a progressively reduction in the following years (150-200 complaints/year). This is mainly due to three factors:

1) a greater awareness of the citizens about the Municipality's activity in noise-related issues;

2) the entry into force of regulations and administrative measures protecting the population from noises due to technical plants and production machineries;

3) the recent installation of equipment technologically more advanced and less noisy.

\section{B. Trend of complaints for type of annoying source and} activity

The trend of complaints across the years depending on the type of annoying source is showed in Fig. 5.

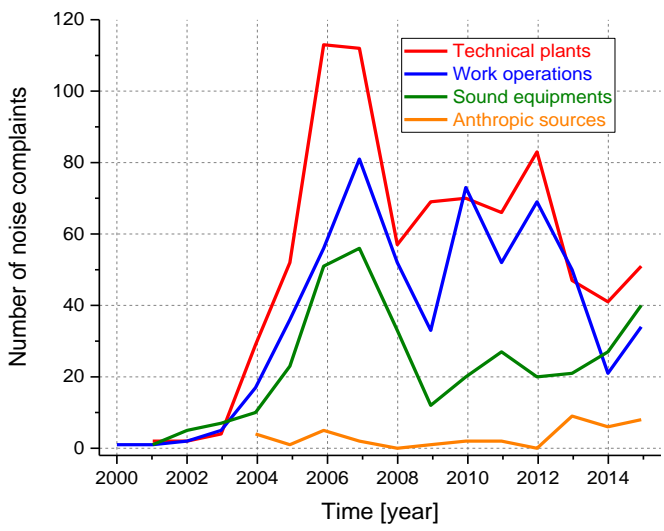

Fig 5 trend of noise complaints due to the type of noise source

Most of the complaints are due to noise emissions of technical plants (air conditioning systems, cold store systems, industrial machines, etc.), sound equipment, activities linked to work operations (bays, construction or industrial handling vehicles, etc.). The number of complaints due to anthropic sources is rather limited. However, music and anthropic noises have increased during the last years, mainly because of the upsurge in public commercial establishments (pub, restaurant) with music entertainment in the city of Milan.

The yearly trend shows a gradual reduction of the complaints (up to 30-60 complaints/year/source) due to a larger use of noise reduction actions, the displacement of most of the annoying activities (such as production activities) from downtown to the suburbs and the entry into force of more restrictive measures and laws.

In Fig. 6 the trend of complaints depending on the type of reported annoying activities is shown. Most of the complaints refer to public commercial activities both generic (supermarket, theatre, cinema, shop, etc.) and with retail and catering businesses (lounge bar, pub, clubhouse, etc.). Industrial activities, crafting and service activities, even if important, do not contribute as much as public commercial ones do. This outcome is due to the displacement of high impact activities from downtown to the suburbs, encouraged 
by the municipality. The number of activities related to "leisure time" shows a slightly increasing trend as a result of a greater interest of youngsters in such meeting places.

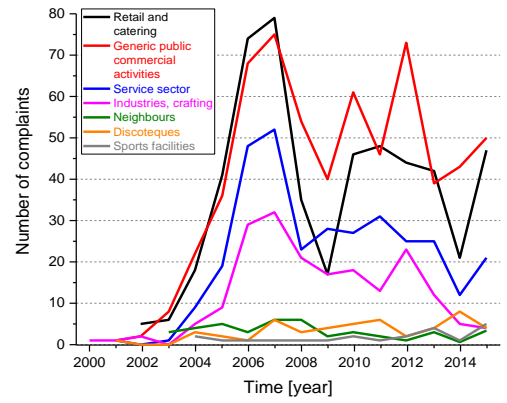

Fig 6 trend of complaints depending on the type of annoying activity (years 2000-2015)

In general, the yearly trend pattern shows three phases: an initial phase with a limited number of complaints/year in which citizens start to contact the Municipality, an intermediate phase with a growing number of complaints/year, and a more recent one with an almost constant rate.

Fig. 7 provides a summary of the results on the different types of disturbing sources and activities reported by the citizens during the period 2000-2013.

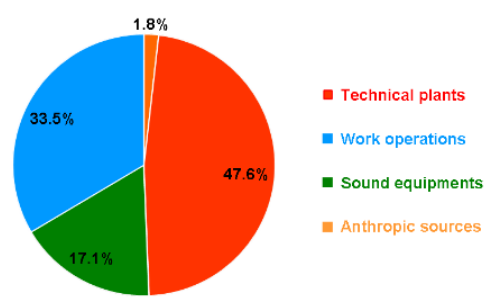

b)

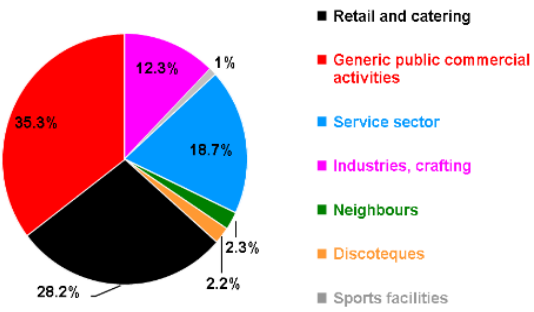

Fig 7 types of disturbing noise sources a) and business/leisure activities b) reported by the citizens during the period 2000-2013

The large percentage of technical installations is mainly due to their widespread distribution as they include air conditioning systems, cold storage systems, electrical generators installed in shops, apartment buildings, supermarkets, offices, small and medium-sized enterprises.

Regarding the impact of business/leisure activities, public commercial establishments represent two-thirds of the overall reported complaints, followed by service and industrial activities. In the years to follow, the number of reported complaints related to production activities has significantly decreased, whereas those connected to leisure-time and sports centers show an opposite trend. In a more detailed analysis, each reported activity has been associated with the corresponding type of annoying source, as shown in Fig. 8.

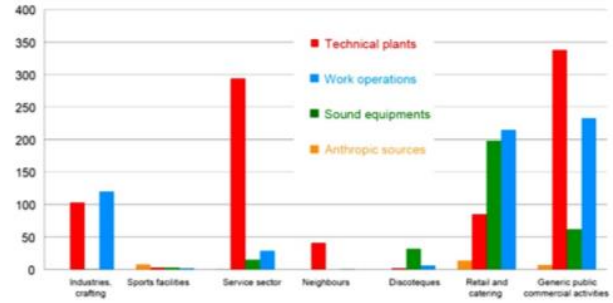

Fig 8 summary of the reported activity as a function of the type of annoying source during the period 2000-2013

The sources denoted as "technical plants" and "sound equipment" are the most annoying ones. The comparison between generic public commercial activities (supermarket, theatre, cinema, pastry shop, boutique, bakery's, etc.) and retail and catering businesses (lounge bar, pub, disco, clubhouse, etc.), shows that technical installations are predominant in the former, whereas music is the most frequent in the latter. The anthropic source gives a minor contribution to public commercial activities, owing to the overlapping with the field performance of activities (referred to as "work operations" in Fig. 8), whereas in retail and catering activities a higher number of complaints due to anthropic source is observed. The most annoying sources linked to industrial activities are technical installations and work operations (bays, cranes, lifting devices, etc.). Fig. 8 also shows a clear predominance of technical installations in service activities and apartment buildings (neighbours). Sports activities are mainly interested by noise of anthropic origin, sound equipment and technical installations.

\section{Outcome of complaint actions and remediation}

The outcome of the complaint actions for the years 20002013 is reported in Fig. 9. Most of the procedures were dismissed and about half of them solved by an action of acoustic remediation.

Fig. 10 shows the implemented remediation actions for the complaint procedures in the years 2014-2015: the direct intervention on the annoying source, because of its effectiveness, is favored (52\%) together with acoustic insulation (35\%). Secondary remediation deals with the change of operation mode (opening/closure times changes, music volume control, etc.).

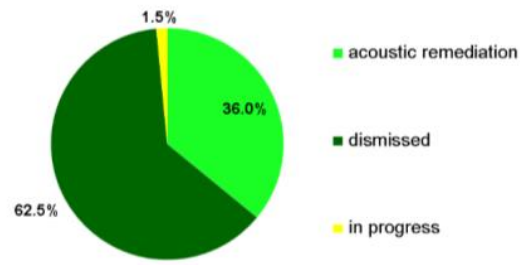

Fig 9 Outcome of the noise complaint actions 


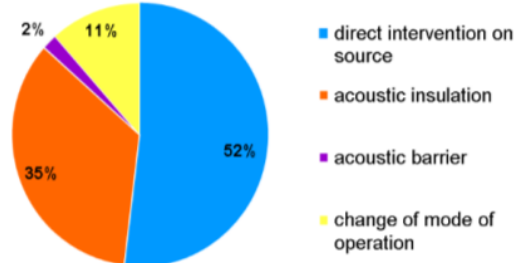

Fig 10 acoustic remediation: implemented actions (years 2014-2015)

Regarding the procedure duration, more than $50 \%$ of them, on average, were completed within two years since the submission date to the Municipality (years 2000-2013), and this percentage increases up to $75 \%$ in the two following years.

\section{Spatial Analysis}

In this study, GIS technology has been used to describe the spatial distribution of the collected complaints through the years 2000-2015, according to the type of source and the noisy activities. Finally, GIS spatial analysis has been applied to calculate density maps, after the assignment of an identification code to each complaint associated to its address. Figure 11 shows the distribution of georeferenced complaints for the years 2000-2015.

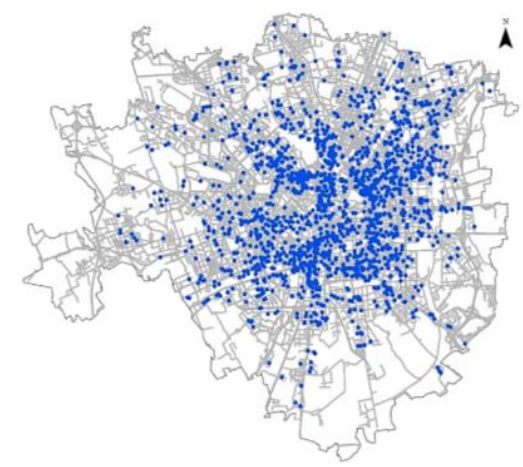

Fig. 11 distribution of reported noise complaints (years 2000-2015) in the city of Milan

With appropriate geodatabase's queries, it has been possible to create maps related to the spatial distribution of complaints sorted by noise sources (Fig. 12a) and annoying activities (Fig. $12 b)$. a)
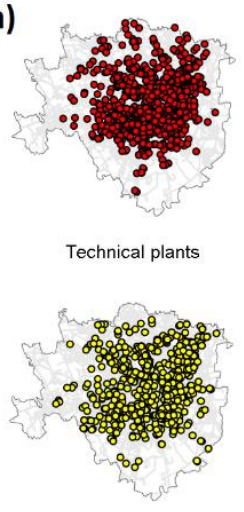

Work operations

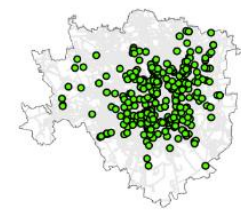

Sound equipments

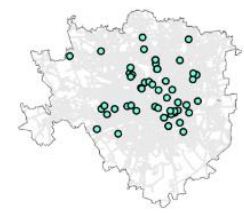

Anthropic sources b)
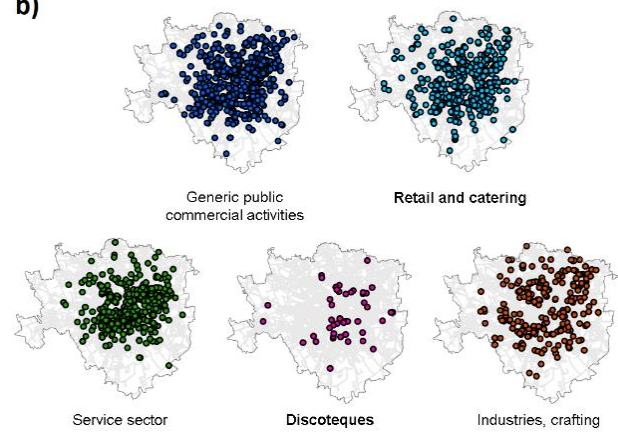

Fig 12 distribution in the city of Milan of noise sources a), and annoying activities b); years 2000-2015

The most annoying sources, such as working activities, music and technical facilities, are widespread within the city and show a spatial distribution in good agreement with the presence of commercial activities such as pubs, cafes, restaurants and shops, mainly concentrated in the central area of Milan.

For the data clustering, a classification into five groups has been performed using the Jenks natural breaks optimization method for non-normal distributions [24]. This method identifies class intervals (bins) in the points of discontinuity of a series of values by seeking to minimize each class's average deviation from the class mean, while maximizing each class's deviation from the means of the other groups. In other words, the method seeks to reduce the variance within classes and maximize the variance among classes. Fig. 13 shows that the highest density of complaints is observed in the "historical" city centre. Moreover, there are other areas of high density of complaints close to the city's boundaries. For a deeper understanding of the real density distribution of complaints, a spatial analysis based on complainants' addresses has been performed.

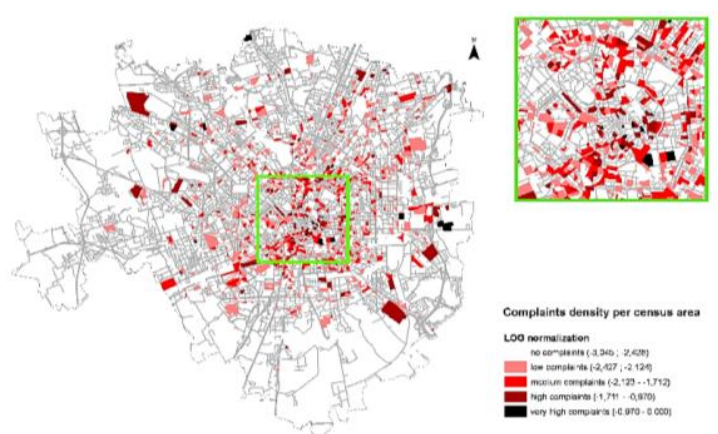

Fig 13 Complaint density per number of inhabitants per census area (years: 2000-2015) divided into five classes. The range of each class refers to the logarithm of normalized complaints per number of inhabitants per census area

The map shown in Fig. 13 has been obtained through the use of the "Kernel Density Estimation" (KDE) tool, e.g. a nonparametric way to estimate the probability density function of a random variable and that allows to identify areas with high density of complaints (hot spots) [25], [26]. This geostatistical technique is widely applied in the geographic 
interpretation of social and economic phenomena, such as the car accidents [27] or the crime mapping [28], and it could be fruitfully used also for the purposes of this study. The KDE algorithm calculates the density of "occurrences" around a given spatial interval. Therefore, the crucial phase of KDE analysis is the choice of the bandwidth, that is, the reference search radius for the interpretation of spatial correlation between points (noise complaints in this case). Equation (1) has been used for the calculation of the Search Radius, SR [24]:

$S R=0.9 \cdot \sqrt{\frac{1}{\ln (2)}} \cdot D_{m} \cdot n^{-0.2} \quad[\mathrm{~m}]$

where $\mathrm{D}_{\mathrm{m}}$ is the median distance of all data with respect to the centroid of the statistical sample $\left(D_{m}=676.1 \mathrm{~m}\right)$ and $\mathrm{n}$ is the sample number $(\mathrm{n}=2151$, total number of complaints). The obtained SR is $628.75 \mathrm{~m}$. Furthermore, in order to represent correctly the real number of citizens affected by a noise exposure, different weight has been associated with each point, namely weight " 1 " has been attributed to individual complaints, while weight " 2 " to collective complaints. The results, shown in Fig. 14, have been divided into 5 classes (density levels), with the exclusion of zero values, according to the Natural Break classification method (the Jenks algorithm) used for non-normal distributions [24]. The grid dimension is $50 \mathrm{~m} \times 50 \mathrm{~m}$. Fig. 14 shows critical areas (red color on the map) with two other smaller hot spots characterized by a number of complaints between 114 and 195 per square $\mathrm{km}$. The identified areas are well-known as noisy places with a high density of food and entertainment services related mainly to the nightlife. The anthropic night activity in these areas related to social gathering is also known as "movida".

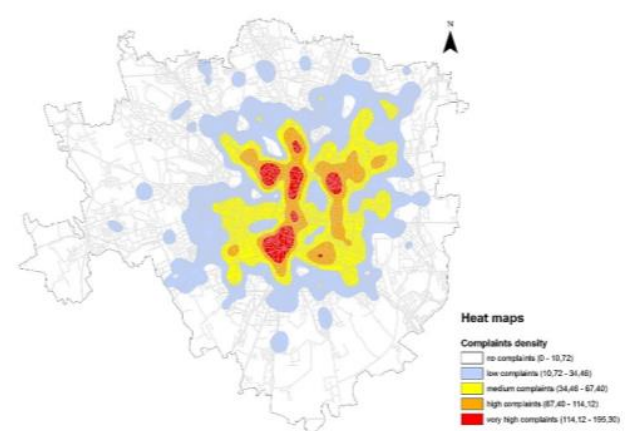

Fig 14 density map of the noise complaints submitted to the Municipality (years 2000-2015). The intervals refer to the number of complaints per unit surface (square $\mathrm{km}$ )

\section{E. Analysis of noise limit exceedances}

Regarding noise annoyance, the Italian legislation requires that the difference between the ambient noise, measured in a room in presence of the disturbing noise, and the background noise, measured in the same position without the sound immission of the disturbing source, both in terms of Aweighted equivalent continuous level $\mathrm{L}_{\text {Aeq }}$, must not exceed 5 $\mathrm{dB}$ during the day-time $(06-22 \mathrm{~h})$ and $3 \mathrm{~dB}$ during the night- time period (22-06 h). This criterion cannot be applied when the ambient noise is:

1) below either 50 or $40 \mathrm{~dB}(\mathrm{~A})$ during day-time and nighttime, respectively, with window open;

2) below either 35 or $25 \mathrm{~dB}(\mathrm{~A})$ during day-time and nighttime, respectively, with window closed.

According to the above criteria, applied by the Regional Agency for Environmental Protection (ARPA), the complaints data for the years 2014-2015 have been analyzed considering the outcome of the inspections by local authorities. Among the 120 cases available, the majority of them observed in the night-time period. Fig. 15 shows the distribution of the outcomes for day-time and night-time periods. The latter period is more critical with $72.3 \%$ cases of exceedance versus $53.3 \%$ observed in the day-time period. A further analysis in terms of business/leisure activities involved (Fig. 16) shows that during day-time commercial activities are the most frequent sources of limits exceedances (47.1\%), followed by services $(23.5 \%)$, while during night-time retail and catering activities (restaurant, bar, pub, clubhouse, etc.) become the most frequent sources of limits exceedances (52.3\%), followed by commercial activities $(33.8 \%)$. Furthermore, during the night-time, exceedances of noise limits are observed also for discotheques (7.7\%) and neighbours (1.5\%).
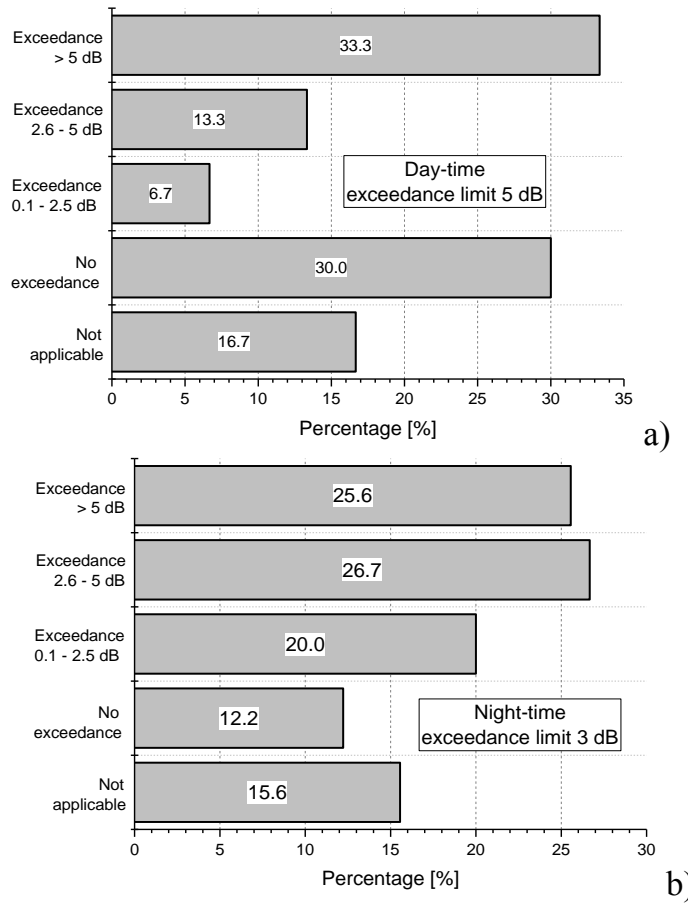

Fig. 15 exceedances of the noise limits resulted from the inspections by local authorities in day-time a) and night-time b) 


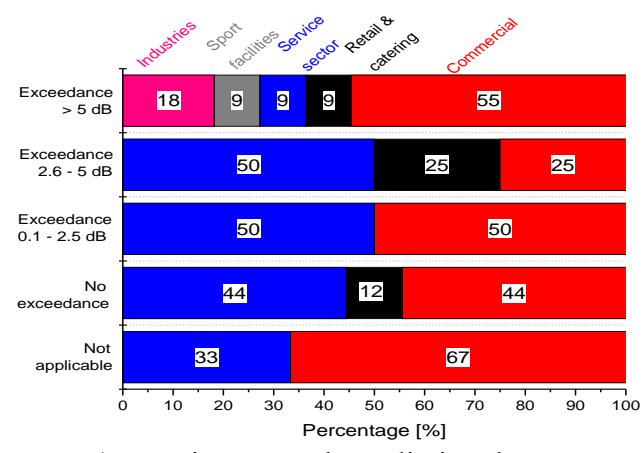

a) Day-time exceedance limit $5 \mathrm{~dB}$

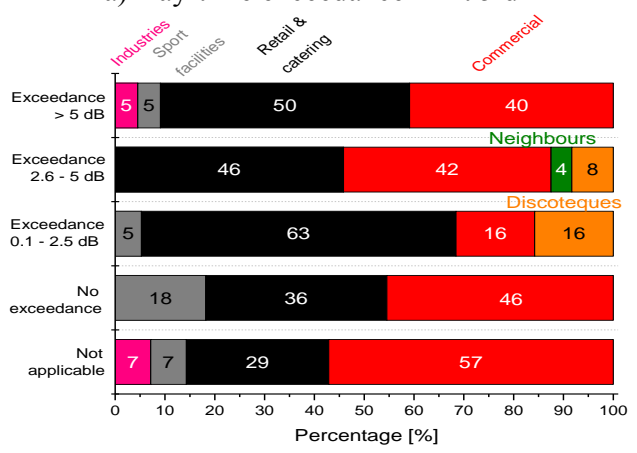

b) Night-time exceedance limit $3 \mathrm{~dB}$

Fig 16 exceedances of the noise limits observed for type of activities involved during day-time a) and night-time b)

It is interesting to point out that during day-time the noise limits exceedances have been observed in the majority of cases $(78 \%)$ with windows open, most likely because the disturbing source is outside the annoyed house, while in the night-time the noise limits exceedances are more frequent (58\%) with windows closed, most likely because the disturbing source is structurally linked to the annoyed house and/or low frequencies are predominant in the noise immission.

\section{F. Noise in urban areas: development of planning policies} and integrated management

The analysis of noise complaints in a large city such as Milan allowed examining the procedure for their management from the activation of administrative processes to the on-site compliance check by ARPA agency (Regional Agency for Environmental Protection). At present, this procedure shows some criticalities due to a poor organization of the flux of information (paperwork-based procedure, partially digitized archive) leading to a non-optimized management of administrative processes (delays and/or non-completion of cases, efficacy of interventions of ARPA, etc.).

For the complaints of citizens dealing with public order offence, an information system of management of incoming calls to the local Police Dept. has been already operating in Milan for many years; the system allows to file the submissions and to support the check during all the steps of the procedure. A similar procedure (user friendly and computer-based) would be also beneficial to manage noise pollution complaints. A web-based platform should enable citizens the access to initiate a complaint procedure, providing all necessary information (including address and geo- localization using WebGIS), the subsequent taking-over by the public authorities, the interaction with ARPA for any possible field measurements, the evaluation of the efficacy of remediation with the possible charge of administrative sanctions. Such IT-tool would also allow for a more efficient stewardship for most critical complaints or with high spatial density, such as the night-life phenomenon, known as "movida", or authorizing ongoing activities by means of exemption (construction sites). In these cases, the public administration would reply faster with proper actions in case of urgency (operative dispositions, ordinances, suspension of activities, oblige of remediation) and carry out actions and guidelines over medium-long periods (rules, integrated planning instruments for acoustic issues, concessions, authorizations, etc.).

\section{CONCLUSIONS}

Nowadays, the sources causing noise pollution in urban areas have several characteristics and an intrinsic complex nature. The present study, through data processing and the analysis of noise complaints, will help elicit further understanding on this issue in the city of Milan with a productive and economic specificity. The analysis on noise complaints submitted since 2000 allowed to identify the sources and activities primarily responsible of noise annoyance, as well as the areas with major noise impact. An interesting result is that the noise from transport infrastructures, though widespread both in time and space, does not represent the main disturbing source of the population in a large city, whereas technical plants, work/anthropic activities result to be the most frequent sources of complaints. The results show that, since 2007, the number of noise annoyance complaints (about 100-150 complaints/year) remains almost constant. Spreading of leisure activities, malls, exhibition centers and venues will likely determine a further increase of complaints in the next future (this trend is already observed for the years 2014-2015). Thus, municipal authorities will have to reconcile the protection of the residents with the increasing demands for new activities.

Beside the local interest of the analysis, the developed methodology through a GIS software allowed to determine the spatial distribution of complaints considering both the noise source categories and the disturbing activities. Further developments of the present work will be aimed at the continuous updating of the database, the implementation of public opinion polling; the analysis of health-related, social and economic issues (housing depreciation); the analysis of complaints and requests for actions addressed to the municipality and, finally, the analysis of night-life social gatherings for leisure purposes known as "movida".

The results of this study outline not only the importance of the exchange of information, cooperation and participation of governmental organization with scientific institutions, but also the need of public participation and involvement to define priorities in legal regulations, especially in solving environmental pollution problems at society level. Thus, the European Directive [29] and its recent revision [30] represent 
a partial answer to the real expectation of the population in terms of noise exposure control. Indeed, in these last years EU policies and guidelines mainly focused on the noise produced by main transport infrastructures such as airports, roads and railways, strongly recommending the use of noise maps and action plans. The outcome of this study would encourage to shift the attention of governmental organization also on other noise sources, especially in urban areas, and to include the complexity of urban soundscape into the current regulatory system, hopefully, also under the stimulation of similar researches in other large cities.

\section{ACKNOWLEDGMENT}

The authors wish to thank the department "Area Ambiente ed Energia - Unità Agenti Fisici e Pianificazione Energetica" of the Municipality of Milan (Caterina Padovani, Morena Borgonovo, Daniele Drago) for sharing the data and their fruitful cooperation.

\section{References}

[1] World Health Organization (WHO), "World Health Report: Prevention of Noise-Induced Hearing Loss" World Health Organization, Geneva, 1997.

[2] European Commission Working Group Dose/Effects, "Position paper on dose response relationships between transportation noise and annoyance" European Communities, 2002.

[3] European Environment Agency, "Quiet areas in Europe" Report No 14/2016, 2016.

[4] K. Paunović, B. Jakovljević, G. Belojević, "Predictors of noise annoyance in noisy and quiet urban streets" Sci. Total Environ., vol. 407, 2009, pp. 3707-3711

[5] H.Y. Phan, T. Yano, H.A. Phan, T. Nishimura, T. Sato, Y. Hashimoto, "Community responses to road traffic noise in Hanoi and Ho Chi Minh City" Appl. Acoust., vol. 71, 2010, pp. 107-114.

[6] J. Méline, A. Van Hulst, F. Thomas, N. Karusisi, B. Chaix, "Transportation noise and annoyance related to road traffic in the French RECORD study” Int. J. Health Geogr., vol. 12, 2013, 44.

[7] Benocci R., Molteni A., Cambiaghi M., Angelini F., Roman H.E., Zambon G., "Reliability of Dynamap traffic noise prediction" Applied Acoustics, vol. 156, 2019 pp. 142-150.

[8] G. Zambon, R. Benocci, A. Bisceglie, H.E. Roman, "Milan dynamic noise mapping from few monitoring stations: Statistical analysis on road network" Proc. Inter-Noise, Hamburg, Germany, 21-24 August ,2016.

[9] Benocci R., Confalonieri C., Roman H.E., Angelini F., Zambon G., "Accuracy of the dynamic acoustic map in a large city generated by fixed monitoring units" Sensors, vol. 20, 2020, 412.

[10] C. Guarnaccia, "Advanced Tools for Traffic Noise Modelling and Prediction" WSEAS TRANSACTIONS on Systems, vol. 12, 2013, issue 2, pp.121-130.

[11] C. Guarnaccia, J. Quartieri, N.E. Mastorakis, C. Tepedino, “ Development and Application of a Time Series Predictive Model to Acoustical Noise Levels" WSEAS TRANSACTIONS on Systems, vol. 13, 2014, pp. 745-756.

[12] G. Brambilla, C. Confalonieri, R. Benocci, "Application of the intermittency ratio metric for the classification of urban sites based on road traffic noise events" Sensors, vol. 19, 2019, 5136.

[13] G. Brambilla, R. Benocci, C. Confalonieri, H.E. Roman, G. Zambon, "Classification of Urban Road Traffic Noise based on
Sound Energy and Eventfulness Indicators", Appl. Sci., vol. 10, 2020, 2451.

[14] R. Guski, D. Schreckenberg, R. Schuemer, "WHO Environmental Noise Guidelines for the European Region: A Systematic Review on Environmental Noise and Annoyance" Int. J. Environ. Res. Public Health, vol. 14 2017, 1539.

[15] H.M.E. Miedema, H. Vos, "Noise annoyance from stationary sources: relationships with exposure metric day-evening-night level (DENL) and their confidence intervals" J. Acoust. Soc. Am., vol. 116, 2004, pp. 334-343.

[16] E. Pedersen, K. Persson Waye, "Perception and annoyance due to wind turbine noise - a dose-response relationship" J. Acoust. Soc. Am., vol. 116, 2004, pp. 3460-3470.

[17] G.C. Avery, "Comparison of telephone complaints and survey measures of noise annoyance" J. Sound Vib., vol. 82, 1982, pp. 215-225.

[18] R. Guski, "An Analysis of Spontaneous Noise Complaints" Environmental Research, vol. 13, 1977, pp. 229-236.

[19] H. Tong, J. Kang, "Noise complaints and its relation to socioeconomic factors at city/region scale in England" Proceedings ICA 2019, Aachen, Germany, 9-13 September, pp. 7043-7048.

[20] Y. Liu, L. Cheshirec, S. Wanga, X. Fu, "A socio-spatial analysis of neighbour complaints using large-scale administrative data: The case in Brisbane, Australia" Cities, vol. 90, 2019, pp. 168180.

[21] N. Akbulut Çoban, K. Gedik, S. Kaya, "A case study on public noise annoyance in relation to research trends on noise pollution" Proceedings EURONOISE Conference, MaastrichtHolland, 31 May-3 June, 2015.

[22] G.A. Luz, R. Raspet, P.D. Schomer, "An analysis of community complaints to noise" J. Acoust. Soc. Am., vol. 73, 1983, pp. 1229-1235.

[23] Law 26 October 1995, n. 447, "Legge quadro sull'inquinamento acustico" (Framework law on noise pollution). Gazzetta Ufficiale 30 n. 254, October 1995, (in Italian).

[24] G.F. Jenks, "The Data Model Concept in Statistical Mapping" International Yearbook of Cartography vol. 7, 1967, pp. 186190.

[25] M. Rosenblatt, "Remarks on Some Nonparametric Estimates of a Density Function" The Annals of Mathematical Statistics, vol. 27, 1956, pp. 832-837.

[26] E. Parzen, "On Estimation of a Probability Density Function and Mode" The Annals of Mathematical Statistics, vol. 33, 1962, pp. 1065-1076.

[27] L. Thakali, T.J. Kwon, L. Fu, "Identification of crash hotspots using kernel density estimation and kriging methods: a comparison" Journal of Modern Transportation, vol. 23, 2015, pp. 93-106.

[28] T. Hart, P. Zandbergen, "Kernel density estimation and hotspot mapping: Examining the influence of interpolation method, grid cell size, and bandwidth on crime forecasting" Policing: An International Journal, vol. 37, 2014, pp. 305-323.

[29] EU Directive, Directive 2002/49/EC of the European Parliament and the Council of 25 June 2002 relating to the "assessment and management of environmental noise", O. J. Eur. Commun. L189/12, 2002.

[30] European Commission, "Report from the Commission to the European Parliament and the Council on the Implementation of the Environmental Noise Directive" in Accordance with article 11 of Directive 2002/49/EC. COM/2017/0151 Final, European Commission: Brussels, Belgium, 2017.

\section{Creative Commons Attribution License 4.0 (Attribution 4.0 International, CC BY 4.0)}

This article is published under the terms of the Creative Commons Attribution License 4.0 https://creativecommons.org/licenses/by/4.0/deed.en_US 